\title{
Infodemia e construção sígnica - movimentos responsivos sob a retórica da pós-verdade
}

\author{
Fernanda Santana Gomes* \\ Maria Angela Paulino Teixeira Lopes**
}

\section{Resumo}

Sob a retórica da pós-verdade, a infodemia e a desinformação atingiram grandes proporções, com impactos negativos na esfera social (KALIL; SANTINI, 2020; ORGANIZAÇÃO MUNDIAL DA SAÚDE, 2020), gerando um cenário de instabilidade, marcado por imprecisão, medo, marginalização e preconceitos. Visando contribuir para as práticas de letramento em leitura nas instâncias formativas, especialmente as educacionais, neste artigo iremos explorar o fenômeno da desinformação (ALLCOTT; GENTZKOW, 2017; WARDLE; DERAKHSHAN, 2017), tomando como objeto analítico o discurso de abertura do presidente Jair Messias Bolsonaro, na $75^{\mathrm{a}}$ Assembleia Geral da Organização das Nações Unidas, proferido em setembro de 2020. Grande parte desse discurso consiste em informações imprecisas e desprovidas de argumentos fundamentados, sobretudo no que se refere ao contexto da pandemia de covid-19 no Brasil e à destruição de biomas brasileiros de extrema relevância para o ecossistema mundial. Considerando o evento enunciativo em análise, buscamos compreender e problematizar como as posições avaliativas do enunciador, atravessadas pelos valores

* Pontifícia Universidade Católica de Minas Gerais (PUC Minas). Doutoranda em Linguística e Língua Portuguesa, bolsista CAPES. Integrante do NELLF/PUC Minas (Núcleo de Estudos em Letramentos, Linguagens e Formação). ORCID: https:// orcid.org/0000-0003-2758-7369.

* Pontifícia Universidade Católica de Minas Gerais (PUC Minas). Doutora em Estudos Linguísticos (UFMG). Pós-doutoramento realizado na Universidade Grenoble Alpes. Professora (adjunta IV) do Programa de Pós-graduação e do Departamento de Letras da PUC Minas. Pesquisadora integrante do NELLF/PUC Minas (Núcleo de Estudos em Letramentos, Linguagens e Formação). ORCID: https://orcid.org/0000-0002-0627-9546. 
ideológicos do(s) lugar(es) que ocupa no contexto sóciohistórico, podem ser capazes de afetar a interlocução com a sociedade. Com a pretensão de atingir o objetivo proposto, recorremos ao aporte teórico desenvolvido pelo círculo bakhtiniano, especialmente, os conceitos de responsividade, posicionamento axiológico e refração (BAKHTIN, 2011, 2017; VOLÓCHINOV, 2013, 2017), e a considerações acerca do discurso polêmico construído sob o viés do dissenso (AMOSSY, 2015, 2017).

Palavras-chave: Desinformação. Infodemia. Responsividade. Axiologia. Formação do leitor.

\title{
Infodemic and Signic Construction - Responsive Movements Under the Rhetoric of Post-Truth
}

\begin{abstract}
Under the rhetoric of post-truth, infodemia and misinformation reached large proportions, with negative impacts on the social sphere (KALIL; SANTINI, 2020; ORGANIZATION MUNDIAL DA SAÚDE, 2020), generating a scenario of instability, marked by imprecision, fear, marginalization and prejudices. Aiming to contribute to reading literacy practices in formative instances, especially educational ones, in this article we will explore the phenomenon of misinformation (ALLCOTT; GENTZKOW, 2017; WARDLE; DERAKHSHAN, 2017), taking as an analytical object the opening speech of the President Jair Messias Bolsonaro, at the 75th General Assembly of the United Nations, delivered in September 2020. Most of this speech consists of inaccurate information and devoid of substantiated arguments, especially with regards to the context of the covid-19 pandemic in the Brazil and the destruction of Brazilian biomes of extreme importance to the world
\end{abstract}


ecosystem. Considering the enunciative event under analysis, we seek to understand and problematize how the evaluative positions of the speaker, crossed by the ideological values of the place(s) it occupies in the socio-historical context, may be able to affect the dialogue with society. In order to achieve the proposed objective, we resorted to the theoretical support developed by the Bakhtinian Circle, especially the concepts of responsiveness, axiological positioning and refraction (BAKHTIN, 2011; 2017; VOLÓCHINOV, 2013; 2017), and considerations about the controversial discourse constructed under the bias of dissent (AMOSSY, 2015; 2017).

Keywords: Disinformation. Infodemic. Responsiveness. Axiology. Reader training.

Recebido em: 11/07/2021 // Aceito em: 10/09/2021. 
A crise contemporânea é, fundamentalmente, a crise do ato contemporâneo. (BAKHTIN, 2017, p. 115).

\section{Introdução}

Diante das intensas e dinâmicas mudanças ocorridas nos processos infocomunicacionais devidas ao avanço tecnológico, houve a emersão de um complexo problema social, a infodemia (KALIL; SANTINI, 2020; ORGANIZAÇÃO MUNDIAL DA SAÚDE, 2020). Esse fenômeno pode desencadear e/ou acentuar o caos social, visto que a informação falsa ou manipulada afeta as interações humanas interferindo diretamente no comportamento da sociedade. Sob o contexto da pandemia de covid-19, a correlação entre desinformação, infodemia e caos social parece ser bem estreita, dado que os problemas ultrapassam o crivo da saúde pública e apresentam expressiva repercussão no estado das relações político-econômicas e sociais, tanto no âmbito nacional quanto no internacional. ${ }^{1}$

A produção, o consumo, a circulação e a reprodução de desinformações promovem significativos impactos sociais, históricos, políticos, econômicos e culturais. Nessa medida, a desinformação tende a favorecer o crescimento do ceticismo, da desconfiança, do pessimismo e da insegurança no âmbito social. Na esfera política, as relações entre nações podem ficar estremecidas, a ponto de inviabilizarem o diálogo, a convivência respeitosa e o intercâmbio comercial. No eixo econômico, a desinformação pode gerar oscilações e especulações financeiras

\footnotetext{
1 Optamos por não utilizar o termo "fake news", pois, além de não abranger a complexidade do fenômeno do falseamento das informações, tornou-se um termo recorrentemente usado por políticos, no ataque à liberdade de expressão e de imprensa. Ver mais em: https://history.uol.com.br/microsites/a-verdade-da-mentira/noticias/por-que-nao-e-certo-usar-o-termo-fake-news-epor-que-usaremos-mesmo-assim. Acesso em: 27 jun. 2021.
} 
expressivas, assim como barreiras comerciais. No âmbito sociocultural, pode favorecer o crescimento de posicionamentos e práticas de intolerância entre sujeitos e nações, propiciando a cultura da marginalização, a xenofobia, os movimentos contra a migração, o sentimento de medo, enfim, as mais variadas práticas de violência e de manifestações de ódio que assolam a humanidade. Na esfera educacional, amplia-se a responsabilidade dos formadores de leitores - professores, agentes comunitários, bibliotecários, entre outros - no sentido de desenvolver práticas de leituras que propiciem reflexões sobre o intrincado processo de constituição e disseminação da desinformação.

Em meio à infodemia intensamente propagada na sociedade, o fenômeno da desinformação (ALLCOTT; GENTZKOW, 2017; WARDLE; DERAKHSHAN, 2017) tem gerado diversos questionamentos, dado que o anseio pela "verdade", por aquilo que é legitimado como verídico, encontra-se obscurecido na esfera social devido ao crescimento do movimento da pósverdade e da adesão a seus princípios.

Almejando flagrar e compreender como esse fenômeno pode afetar a sociedade, selecionamos, como objeto de análise, o discurso de abertura do presidente Jair Messias Bolsonaro na 75 Assembleia Geral da Organização das Nações Unidas (ONU), em setembro de 2020. ${ }^{2}$ Trata-se de um tecido discursivo em que predomina a argumentação, por meio de informações imprecisas e sem fundamentação, principalmente a respeito do cenário da pandemia de covid-19 no Brasil e da destruição da floresta amazônica e do Pantanal, biomas de grande significância para a humanidade.

$\overline{2} \quad$ A $75^{\text {a }}$ Assembleia Geral da ONU foi realizada sob a modalidade virtual. O discurso do presidente foi apresentado por meio de um vídeo gravado. Consultar: <https://www.funag.gov.br> (transcrição) e https://m.youtube.com/watch?v=14K9Tk5z-po (vídeo). Acesso em: 20 mar. 2021. 
A fim de alcançar o que propomos, apresentaremos, na primeira seção deste artigo, as conceituações teóricas referentes à infodemia (KALIL; SANTINI, 2020; ORGANIZAÇÃO MUNDIAL DA SAÚDE, 2020) e ao fenômeno da desinformação (ALLCOTT; GENTZKOW, 2017; WARDLE; DERAKHSHAN, 2017) sob o contexto da pós-verdade. Na segunda seção, abordaremos os conceitos de signo e ideologia, cunhados nos estudos desenvolvidos pelo círculo bakhtiniano (BAKHTIN, 2011; 2017; VOLÓCHINOV, 2013; 2017). Evidenciamos, nesse percurso, a importância desses pressupostos teóricos para a compreensão das práticas discursivas empregadas na situação concreta da enunciação. Uma breve descrição da situação sócio-histórica em que o pronunciamento do presidente Bolsonaro foi proferido será apresentada na terceira seção deste estudo, seguida por movimentos analíticos voltados para o funcionamento discursivo, com foco no modo como os temas são explorados pelo enunciador. De modo a apreender os movimentos constitutivos do tecido argumentativo, buscar-se-á o diálogo entre o conceitual teórico de base bakhtiniana sobre o signo ideológico e as reflexões trazidas por Amossy (2015; 2017) acerca do discurso polêmico, construído sobre o dissenso.

Para concluir, teceremos algumas considerações, avaliando o potencial do pronunciamento em exame como ato responsivo, atravessado por posicionamentos ideológicos e, portanto, valorados, orientado para determinados fins e capaz de suscitar a disseminação de crenças e pré-conceitos que podem cristalizarse de modo a se constituírem como verdades. Nesse movimento, retomaremos a necessidade de investir em atividades de leitura que tomem os textos em circulação nas esferas públicas midiáticas a partir da compreensão das estratégias de engendramento das (des)informações. 


\section{Infodemia sob a retórica da pós-verdade}

A sociedade contemporânea vive a desordem informacional, caracterizada a partir de três noções distintas: desinformações, informações incorretas e más informações. A desinformação refere-se a informações falsas, criadas deliberadamente com a pretensão de prejudicar pessoas, grupos sociais, organizações e países. Embora sejam falsas, as informações incorretas não têm a finalidade de provocar danos. Por sua vez, as más informações são baseadas na realidade com o propósito de gerar conteúdos e dados a pessoas, organizações e países (WARDLE; DERAKHSHAN, 2017).

Embora mais facilmente disseminada no contexto hodierno, a desinformação é considerada um fenômeno antigo, isso porque a sociedade sempre foi influenciada por informações erradas, mentiras deliberadas e teorias da conspiração (FRIAS FILHO, 2018). O cenário em que as desinformações se inserem é a de um ambiente democrático e descentralizado, representado pelas mídias sociais, um espaço em que ocorre a conexão entre indivíduos (CASTELLS, 2012). Nesse enquadre, a possibilidade de compartilhamento de informações (DAVENPORT, 1994) representa um aspecto bastante significativo.

A estrutura do ecossistema da informação, construída em torno de plataformas digitais poderosas, as quais têm atuação como intermediárias de informação, acentua o fenômeno da desinformação, dado que realiza a reprodução e a disseminação das notícias com abrangência e velocidade incomuns (SYED, 2017). Isso ajuda a ampliar os efeitos da implantação estratégica de notícias falsas para fins políticos ou comerciais (LEVI, 2018). Outro ponto a se destacar é que as barreiras em relação à entrada 
de usuários no setor de mídia diminuíram de forma expressiva, devido à facilidade na criação de sites $\mathrm{e}$, principalmente, pelo fato de ser fácil monetizar o conteúdo da web por meio de publicidade, possibilitando o acesso às grandes plataformas. $\mathrm{O}$ terceiro ponto refere-se ao aumento no uso das mídias sociais, os maiores veículos relacionados à disseminação de notícias falsas. Dessa forma, há, cada vez mais, pessoas expostas às desinformações. A polarização política crescente é outro ponto a se considerar, visto que interfere na probabilidade de cada lado acreditar passionalmente em notícias falsas negativas sobre o outro (ALLCOTT; GENTZKOW, 2017). Nesse sentido, o fenômeno da desinformação tende a ser ampliado progressivamente.

O problema da desinformação relaciona-se diretamente com o desenvolvimento das mídias digitais e a arquitetura da rede. Os usos manipulativos da arquitetura da rede na produção, circulação e ampliação de desinformações sob uma escala cada vez maior, com dificuldades no mapeamento e no processo de compreensão, dificultam a regulação. Sob essa perspectiva, é importante, sobretudo, ter a compreensão de que a arquitetura do ecossistema de informações projeta e organiza o discurso falso com credibilidade e impacto e, até mesmo, estimula a distribuição viral de desinformações nas mídias sociais (LEVI, 2018).

Em 2020, devido à grande difusão e repercussão da pandemia de covid-19 nos diálogos e notícias em todo o mundo, a relação entre mídia e novo coronavírus ${ }^{3}$ ficou cada vez mais intensa e estreita, o que fez instaurar-se o que se denomina "infodemia". Conforme a Organização Pan-Americana da Saúde - OPAS (2020) -, uma divisão da Organização Mundial da

3 Consultar: https://www.paho.org/pt/covid19; http://www.toledo.ufpr.br/portal/artigos-cientificos-covid-19/; https://www. thelancet.com. Acesso em: 29 jun. 2021. 
Saúde (OMS), o termo se refere a um excesso de informações, algumas, muito precisas e outras, não, sendo difícil encontrar fontes idôneas e orientações confiáveis. É “caracterizada por uma quantidade e variedade excessiva de informações de diferente qualidade e credibilidade (algumas falsas, outras imprecisas, outras baseadas em evidências) [...]" (KALIL; SANTINI, 2020, p. 5). Esse enorme volume de informações associadas a um assunto específico pode se multiplicar, de forma célere e exponencial, conforme o teor do evento em questão. Nessa medida, tornam-se comuns o surgimento de rumores e desinformações e a ocorrência de manipulação de informações com intenções duvidosas. Esse fenômeno, portanto, consegue atingir proporções significativas e passa a ser amplificado pelas redes sociais, alastrando-se demasiadamente rápido.

A infodemia impede às pessoas o acesso a fontes e informações fiáveis, o que é suficiente para gerar um grande impacto na esfera social, além de desorientação e perplexidade. Há casos de informações verdadeiras que são mal interpretadas, tornando-se falsas, há outros casos de informações falsas criadas com a pretensão direta de serem interpretadas como falsas, porém acabam sendo lidas e repassadas como verdadeiras. Ademais, há a compreensão de que nem todo conteúdo inexato pode ser considerado como notícias falsas. Esses aspectos são relevantes, pois "a desinformação se expande no mesmo ritmo que a produção de conteúdo, e as vias de distribuição se multiplicam. Assim, a própria infodemia acelera e perpetua a desinformação [...]" (OPAS, 2020, p. 3). Kalil e Santini (2020, p. 6) acentuam a ideia de recursividade, afirmando que "a desinformação produz a 'infodemia' e é produzida por ela [...]”. 
Sob o contexto pandêmico, o termo vem sendo empregado para fazer referência à disseminação demasiada e abusiva de desinformações. Além de causar danos à sociedade, a infodemia contribui para obscurecer a verdade, manipular a população, aumentar e acelerar as condutas irracionais alimentadas pelo medo e frear a eficácia das campanhas e iniciativas de teor positivo.

$\mathrm{Na}$ guerra de (des)informações sob a qual atualmente vivemos, o controle e a manipulação da opinião pública por meio da comunicação midiática têm como fonte de intervenção e interlocução o novo coronavírus. Há a proliferação de "especialistas" que, tendo como referência a web, expressam diferentes pontos de vista, em grande parte contraditórios, podendo causar desorientação, ansiedade e até pânico à sociedade. Essas informações falsas ou enganosas intensificam a resistência generalizada da população, no que se refere à tomada de medidas promovidas por autoridades sanitárias com vistas ao controle de infecções, podendo, consequentemente, causar o atraso de intervenções essenciais. Nesse sentido, as consequências da disseminação de informações sem comprovação científica podem ser muito perigosas em relação à área da saúde, em que é indispensável a aplicação de métodos científicos às práticas médicas. Sob essa ótica, acentua-se a necessidade de formação leitora crítica, a fim de contribuir para a compreensão das implicações e imbricações das redes infocomunicacionais que ancoram e projetam desinformações na esfera social.

Potencialmente capaz de afetar de forma negativa a pandemia de covid-19, a infodemia pode: (a) dificultar a localização de fontes e orientações confiáveis; (b) provocar ansiedade, depressão, sobrecarga e exaustão emocional; (c) 
afetar os processos de tomada de decisão, quando são esperadas respostas imediatas e não há tempo adequado para análise de dados científicos, e d) não conferir um controle de qualidade sobre o que é publicado e, também, sobre as informações utilizadas nas ações e tomada de decisões (OPAS, 2020).

No Brasil, a manipulação midiática por meio de desinformações é comumente exercida em pronunciamentos e outros enunciados proferidos pelo presidente Bolsonaro, que, por meio de uma retórica contundente, manifesta a sua aversão à grande mídia, essencialmente, à imprensa, fomentando relações afetivas com o seu público-alvo e apresentando ambiguidades no tecido discursivo, as quais visam ocultar seu projeto enunciativo.

Neste texto, o discurso de abertura do presidente Bolsonaro na $75^{\mathrm{a}}$ Assembleia Geral da Organização das Nações Unidas (ONU) será analisado à luz da abordagem discursivodialógica dos estudiosos ligados ao Círculo de Bakhtin, com ênfase nas noções de ideologia, signo ideológico, dialogismo, responsividade e responsabilidade, conforme exposição a seguir.

\section{Signo e ideologia sob o viés do dialogismo}

Pensar em princípios teóricos desenvolvidos por Bakhtin (2011; 2017) e Volóchinov $(2013$; 2017) para a discussão da desinformação se justifica pelo fato de esse fenômeno consolidar-se em correspondência direta com a compreensão da língua in actu, conforme uma proposta filosófica e sociológica de se conceber o discurso, concreto, heterogêneo e ininterrupto, sob um viés dialógico.

A reação e o posicionamento dos sujeitos diante do fenômeno da pós-verdade são substanciais para a compreensão das práticas 
sociais e dos processos de interação que são estabelecidos e desenvolvidos na sociedade. Isso porque os discursos, constituídos na "unicidade do evento singular" (BAKHTIN, 2017, p. 42-43), são sempre atravessados por posicionamentos avaliativos e valorativos, portanto, carregados de tensões próprias das interações humanas, "ligadas às condições de dada situação social concreta, e reagem com extrema sensibilidade a todas as oscilações do meio social." (VOLÓCHINOV, 2017, p. 107108). Tendo em vista o caráter híbrido, heterogêneo e instável da linguagem humana, inscrita na historicidade das práticas sociais, também as desinformações, frutos de construto político, social e ideológico, podem ser mais bem apreendidas e explicadas à luz das concepções do círculo bakhtiniano.

Conforme o que preconiza o círculo bakhtiniano, o signo deve ser avaliado como "um fenômeno da realidade objetiva que se tornou fenômeno da realidade ideológica: o objeto se transformou em signo [...]" (VOLÓCHINOV, 2013, p. 192). Referindo-se à palavra, Volóchinov (2013) sublinha que ela é um fenômeno ideológico por excelência, visto que, nos atos comunicativos, os sujeitos apresentam, de forma contínua e intensa, a necessidade de sua utilização no processo de referência a algo no universo. Dessa forma, "o campo ideológico coincide com o campo do signo [...]" (VOLÓCHINOV, 2017, p. 93).

No processo de caracterização do signo, a noção de ideologia é um aspecto essencial. Sob o crivo dessa relação, ideologia é compreendida como "todo o conjunto de reflexos e interpretações da realidade social e natural que se sucedem no cérebro do homem, fixados por meio de palavras, desenhos, esquemas ou outras formas sígnicas [...]" (VOLÓCHINOV, 2013, p. 138). Nessa medida, ideologia consiste nos processos 
de interpretação e de reflexão realizados por cada consciência social, por cada sujeito a respeito do mundo em que está inserido. A noção de ideologia adotada pelo círculo bakhtiniano baseia-se no movimento de reflexão e refração. Assim como o signo é o material da linguagem concretizado, decorrente do que pode ser extraído/captado de um dado externo específico, ele, também, consiste naquilo que se pode reconstruir como seu reflexo.

Concebida como parte integrante do signo, a ideologia não acontece de forma isolada. Conforme o círculo bakhtiniano, havendo significação sígnica, haverá interação dialógica. Nesse sentido, "o signo surge apenas no processo de interação entre consciências individuais [...]" (VOLÓCHINOV, 2017, p. 95). Ressalte-se que o conceito de individualidade é concebido sob o prisma da historicidade do indivíduo. Sendo "responsável por suas ideias e conceitos", o indivíduo é um "fenômeno puramente socioideológico". O "conceito de individualidade, [...] construído sobre o indivíduo natural, é por sua vez uma superestrutura ideológica e sígnica e, portanto, social.” (VOLÓCHINOV, 2017, p. 129).

Sob essa perspectiva, tem-se como evidência que "tudo o que é ideológico possui significação sígnica" (VOLÓCHINOV, 2017, p. 93). Isso significa dizer que o que tem valor no universo pode vir a ser concebido como um signo à medida que conseguir fazer referência a algo para além de si mesmo. Contudo, há de se ter o entendimento de que "o signo não é somente uma parte da realidade, mas também reflete e refrata uma outra realidade, sendo por isso mesmo capaz de distorcê-la, ser-lhe fiel, percebêla de um ponto de vista específico e assim por diante [...]" (VOLÓCHINOV, 2017, p. 93). 
A discussão a respeito da significação sígnica, desenvolvida tanto por Bakhtin como por Volóchinov, ancora-se substancialmente na ideia de valoração, posto que, ao utilizarem palavras na referência a quaisquer coisas externas, os sujeitos sempre as valoram. No construto ideológico das consciências individuais, cada tom valorativo orienta-se pela vivência e pela posição social (VOLÓCHINOV, 2017). Nesse sentido, o tom axiológico, a ideologia e o signo ganham vida nos enunciados (BAKHTIN, 2011). E o discurso somente tem valor como um todo se forem relevados, em conjunto, o sistema linguístico (o aspecto verbal) e o evento discursivo (o aspecto extraverbal).

Relacionando esses aspectos do signo à conjuntura da desinformação, podemos dizer que determinados eventos da realidade objetiva são discursivizados em forma de desinformações devido ao fato de serem refratados por determinadas ideologias, ${ }^{4}$ as quais tendem a formar grupos ideológicos, ou seja, constituem "bolhas" (FERRARI, 2018) que fomentam e projetam perspectivas de mundo semelhantes. Essas bolhas vão se constituindo e se fortalecendo progressivamente sob uma relação sígnica, visto que são refratadas e refletidas na disseminação de outras desinformações.

Devido à comoção causada pelo discurso de outrem, com o qual sujeitos compartilham pontos de vistas afins, as ideologias também ganham vozes na sociedade. O signo, portanto, como material linguístico-ideológico, orienta-se e é orientado pelas forças sociais, pelas relações entre os agentes discursivos na esfera social.

Como um enunciado completo, no sentido bakhtiniano, uma desinformação perpassa o código, pois exige uma leitura de

4 Neste estudo, quando tratamos de ideologia, fazemos referência a uma condição sócio-histórica, constituída por discursos interligados, que formam um conjunto de crenças e conhecimentos, manifestados em posicionamentos valorativos. 
outros elementos extralinguísticos além de um entendimento do conteúdo subentendido. Tendo como base as noções de signo e ideologia que são postuladas pelo círculo bakhtiniano, na seção seguinte, buscaremos demonstrar como os enunciados proferidos pelo presidente Bolsonaro na abertura da $75^{\mathrm{a}}$ Assembleia Geral da ONU - 2020 se constituem como um signo, refletindo e refratando perspectivas de seu criador e outras para as quais estão orientadas.

\section{Nas tramas do discurso - responsividade e mobilização de "verdades"}

Assumindo a abordagem descendente de análise, em consonância comas obras do círculo bakhtiniano, consideraremos, inicialmente, as "condições concretas da vida do texto", em "relação estreita com a interação" (BAKHTIN, 2011, p. 319) de que faz parte, para então, explorarmos os aspectos propriamente textuais e linguísticos que constituem o discurso.

No dia 22 de setembro de 2020, a ONU inaugurava, em sua $75^{\mathrm{a}}$ Assembleia Geral, a década de ação pelos Objetivos de Desenvolvimento Sustentável (ODS), em que líderes globais se comprometiam a acelerar as ações em benefício das pessoas, do planeta, da prosperidade e da paz, valorizando as parcerias multilaterais. Convidado a proferir o discurso de abertura do evento, o presidente Bolsonaro, configurou seu texto, endereçado à comunidade internacional, apoiando-se em estratégias discursivas que vêm pontuando sua trajetória política, desde sua atuação como deputado federal (de 1991 a 2018), até a posse e seu exercício como presidente, a partir de 2019. 
Ao dirigir-se aos interlocutores, no início do seu discurso, o presidente Bolsonaro conclama a necessidade da verdade ${ }^{5}$ para a superação das situações problemáticas ("o mundo necessita da verdade para superar os desafios [...]" $(\S 4)),{ }^{6}$ valendo-se de um dos recursos retóricos mais empregados na campanha à presidência - o uso de palavras de outrem para alicerçar a própria palavra. Além da recorrência a passagens bíblicas, como o versículo comumente usado na época da eleição - "E conhecereis a verdade, e a verdade vos libertará" (João 8:32) -, o presidente Bolsonaro utiliza-se de gestos e slogans alinhados ao estilo militar, como o grito de guerra da Brigada Paraquedista do Exército, apropriado como slogan de sua coligação, "Brasil Acima de Tudo, Deus Acima de Todos".

\subsection{Responsividade e negação da responsabilidade}

Iniciando a argumentação do texto pela estratégia do estabelecimento dos polos - o vírus da covid-19 e a economia -, o presidente Bolsonaro passa a enaltecer as ações empreendidas por ele e pelo seu governo para vencer os desafios enfrentados em seu mandato.

Em relação ao enfrentamento da pandemia covid-19, observam-se, no discurso, tentativas de convencer os líderes dos países membros de que não pode ser responsabilizado pela situação trágica advinda das mortes pela pandemia. Esse expediente aponta claramente para a responsividade que está

\footnotetext{
5 Na perspectiva bakhtiniana, o termo "verdade" pode assumir sentidos diferenciados, uma vez que, em um processo de produção do conhecimento, o ato de conhecer encontra seu objeto de análise perpassado por valores. O ato de conhecer é indispensável como ação investigativa para chegar a verdades ( pravda - noção de verdade temporária, sempre em construção, em movimento - verdade do ser, centro de valor no mundo real) e não à verdade única (istina - noção de verdade teórica de natureza universal, pré-fixada, normatizante, como um dever moral que seja absoluto para todos) (BAKHTIN, 2017).

6 Os parágrafos do texto em análise foram numerados para facilitar o acompanhamento do exame pelo leitor.
} 
na base de todo discurso, conforme definiu Volóchinov (2017, p. 219): "o discurso verbal impresso participa de uma espécie de discussão ideológica em grande escala: responde, refuta ou confirma algo, antecipa as respostas e críticas possíveis, busca apoio e assim por diante.".

Como estratégia de culpabilização e responsabilização, o chefe de governo passa a atribuir parte da responsabilidade aos estados e municípios, os quais, segundo ele, receberam autonomia do Supremo para fazer a gestão da pandemia: "Por decisão judicial, todas as medidas de isolamento e restrições de liberdade foram delegadas a cada um dos 27 governadores das unidades da Federação. Ao Presidente coube o envio de recursos e meios a todo o País [...]" (§7). À imprensa ele conferiu o restante da responsabilidade: "[...] parcela da imprensa brasileira politizou o vírus, disseminando o pânico entre a população [...]” (§8). Essa estratégia de construir para si mesmo um lugar de vítima passa a ser recorrente no fio discursivo do pronunciamento presidencial. Vale ressaltar que a decisão do Supremo Tribunal Federal (STF) de atribuir autonomia a Estados e municípios para tomadas de decisão contra a propagação da covid-19 não exclui a participação e, sobretudo, a responsabilidade e atuação da União.

O movimento responsivo firma-se de modo contundente, na listagem das ações implementadas para deter o vírus e para tomar as medidas econômicas, relativamente às frases "fique em casa" e a "economia a gente vê depois" atribuídas àqueles a quem responsabilizou por causarem o pânico e o "caos social ao país" (§8). Além do objetivo de desqualificar o adversário, tais ações e medidas buscam responder a críticas dirigidas ao comportamento do presidente e sua equipe, os quais, desde o 
início da pandemia, apresentaram um posicionamento totalmente negacionista diante da doença. Matérias jornalísticas publicadas pela imprensa nacional e internacional são vistas pelo presidente como parte de movimentos conspiratórios.

Agenciando recursos linguísticos para mostrar as formas de enfrentamento à covid-19, sem se descuidar da economia, ora o enunciador assume a total responsabilização pelas ações, construindo um ethos de governante em $1^{\text {a }}$ pessoa, ("alertei"; "mantenho"; "reafirmo"), ora atribui os atos ao "Nosso governo", valendo-se de verbos na $3^{\mathrm{a}}$ pessoa do singular ("Concedeu"; "Destinou"; "Assistiu"; "Estimulou”). Para fortalecer e propalar os feitos governamentais, a argumentação se constrói sobre dados numéricos, especialmente quando aponta os recursos e benefícios destinados a suprir as necessidades da população, utilizando-se de operadores discursivos de comparação ("o auxílio emergencial [...] o maior programa de assistência [...] talvez um dos maiores do mundo" (§10)), além de itens lexicais que orientam para a entonação valorativa ("socorro a pequenas e microempresas").

No que se refere ao auxílio emergencial, concedido aos trabalhadores informais e aos cidadãos com condições menos favorecidas do ponto de vista econômico, em decorrência das medidas de isolamento social da pandemia de covid-19, o presidente Bolsonaro infla o valor pago/ a ser pago: "Nosso governo [...]. Concedeu auxílio emergencial em parcelas que somam aproximadamente 1.000 dólares para 65 milhões de pessoas, o maior programa de assistência aos mais pobres no Brasil e talvez um dos maiores do mundo [... $]^{\prime \prime}(\S 10) .^{7}$

\footnotetext{
7 Estas e outras cifras citadas foram posteriormente confrontadas com dados dos principais provedores de informações do País, como o Banco Central do Brasil (BCB), a Fundação Getúlio Vargas (FGV) e o Instituto Brasileiro de Geografia e Estatística (IBGE). Consultar: https://www.google.com/amp/s/g1.globo.com/google/amp/fato-ou-fake/noticia/2020/09/22/veja-o-quee-fato-ou-fake-no-discurso-de-bolsonaro-na-onu.ghtml; $\quad$ https://noticias.uol.com.br/politica/ultimas-noticias/2020/09/22/
} 
$\mathrm{Na}$ continuidade dos argumentos apresentados para exaltar as ações efetivadas diante dos desafios mencionados na abertura, o presidente cita o alto custo dos insumos, a exemplo do componente da hidroxicloroquina, medicamento que, desde o início da pandemia, vinha sendo apontado por ele como a "cura possível" da covid-19. Diante da comunidade internacional, Bolsonaro deixa claro que seu governo defendeu o "tratamento precoce". Embora a eficácia do medicamento no tratamento da doença não tenha sido cientificamente comprovada, o presidente do Brasil continuaria a defender a hidroxicloroquina, o que contribuiu para que grande parcela da população constituída por seus apoiadores a ela recorresse. Cabe ressaltar que a comunidade científica internacional já avaliara que o uso de hidroxicloroquina poderia agravar o risco de outras doenças em decorrência de seus efeitos colaterais. ${ }^{8}$

No cenário da saúde pública, além do incentivo do presidente ao uso de medicamentos cuja eficácia não fora atestada pelos órgãos oficiais, somam-se o frequente desencorajamento ao isolamento social, indispensável à prevenção contra o coronavírus, e a reiterada desqualificação dos conhecimentos científicos e das práticas profissionais, dedicados à proteção e à promoção da saúde. Como forma de manifestar o seu negacionismo científico, o presidente vem desqualificando reiteradamente as orientações de especialistas em medicina sanitária e infectologia, estimulando as aglomerações e o menosprezo pelo vírus e sua letalidade, desdenhando do uso de máscaras e criticando a adoção de medidas para conter a aglomeração, especialmente

8 Consultar: http://conselho.saude.gov.br/ultimas-noticias-cns/1194-nota-publica-cns-alerta-sobre-os-riscos-do-uso-dacloroquina-e-hidroxicloroquina-no-tratamento-da-covid-21; https://saude.abril.com.br/medicina/medicamentos-estao-sendousados-irracionalmente-alerta-farmaceutico; https://www.thelancet.com; http://informe.ensp.fiocruz.br/noticias/48989; https:// scielosp.org/article/physis/2020.v30n2/e300217. Acesso em: 20 mar. 2021. 
o controle de abertura do comércio. Valendo-se da violência verbal (AMOSSY, 2017), uma estratégia do discurso polêmico, chegou a designar como "covardes" aqueles que decidiram seguir o isolamento social como medida mais adequada e efetiva de prevenção recomendada pela OMS. ${ }^{9}$

Segundo Amossy (2017), a sociedade contemporânea é afeita ao espetáculo, a situações em que polêmicas se tornam muito atrativas, visto que apresentam "vencedores", pelos quais se pode torcer, e "perdedores", os quais são ridicularizados e/ ou marginalizados. Devido a essa abertura à espetacularização dos conflitos, polêmicas são fabricadas, por meio de discursos, incitando a manifestação do contraditório, a acentuação dos antagonismos, o embate de opiniões. Um exemplo desse embate pode ser flagrado nesta passagem do discurso de Bolsonaro: "A Amazônia brasileira é sabidamente riquíssima. Isso explica o apoio de instituições internacionais a essa campanha escorada em interesses escusos que se unem a associações brasileiras, aproveitadoras e impatrióticas, com o objetivo de prejudicar o governo e o próprio Brasil."” (\$22).

No corpo de seu projeto enunciativo, o presidente Bolsonaro alimenta a polêmica como o ato de marcar a oposição pela manifestação discursiva que possibilita tensionar a polarização. Dado que a delimitação da diferença é muito significativa do ponto de vista argumentativo do discurso polêmico, ele, comumente, recorre ao uso da dicotomia. Ao construir um discurso sob o viés do dissenso, em que o confronto de opiniões contraditórias consegue ultrapassar os limites de um debate referencial, talvez seja possível que o enunciador consiga a adesão de terceiros, o que significa fortalecimento e ampliação de seu campo de posicionamento discursivo.

9 Consultar: https://noticias.uol.com.br/politica/ultimas-noticias/2020/09/18/bolsonaro-diz-que-fique-em-casae-para-os-fracosconversinha-mole.htm. Acesso em: 01 jul. 2021. 


\subsection{Responsividade, polarização e construção do outro}

De modo semelhante às estratégias de enaltecimento das ações governamentais praticadas por seu governo, agenciadas na primeira parte do discurso ( $§ 1$ a $§ 16)$, o presidente Bolsonaro, ao focalizar o tema da produção agrícola, continua a destacar o êxito do agronegócio brasileiro em consonância com uma suposta preservação ambiental: "Garantimos a segurança alimentar a um sexto da população mundial, mesmo preservando $66 \%$ de nossa vegetação nativa" [...] "E usando apenas $27 \%$ do nosso território para a pecuária e agricultura. Números que nenhum outro país possui." $(\S 25){ }^{10}$

Indubitavelmente, a produtividade da agricultura brasileira é uma das maiores do mundo, e, ao destacar esse setor produtivo, o presidente Bolsonaro busca demonstrar certa dependência do mundo em relação à nação brasileira referentemente à alimentação e ao combate à fome mundial. Ainda que se exiba como celeiro do mundo, nesse setor, o Brasil, de forma contraditória e paradoxal, apresenta índices vergonhosos de um imenso contingente de pessoas que passam fome, segundo o IBGE. ${ }^{11}$

Sob esse aspecto, observa-se a "orientação social da enunciação” (VOLÓCHINOV, 2013, p. 189-191) indiciando a estrutura estilística do enunciado atravessado pelo posicionamento axiológico. O tema - a pujança da agricultura brasileira - se constrói enunciativamente a partir da entonação, isto é, dos elementos de valoração advindos do lugar social do falante. Assim, o posicionamento axiológico do enunciador,

\footnotetext{
10 Consultar: https://biblioteca.ibge.gov.br; https://plataforma.mapbiomas.org; https://dataworldbank.org. Acesso em: 01 jul. 2021.

11 Consultar: https://www.bbc.com/portuguese/brasil-54288952. Acesso em: 27 jun. 2021.
} 
impregnado dos valores de classe e da cultura do sujeito que fala, deixa marcas sobre o todo do enunciado. Nessa medida, ganham espaço os clichês ("O homem do campo trabalhou como nunca, produziu, como sempre" ( $(17))$, as frases feitas e os "lugares comuns" ("A liberdade é o bem maior da humanidade" (§ 55)).

Para Amossy (2015), as fórmulas fixas, as frases feitas, compõem uma "doxa" (ideologema de Bakhtin), ou seja, são constituídas de imagens preconcebidas, próximas dos estereótipos, construídas sob a influência do meio social e histórico como modos de realização do discurso, os quais podem, sob viés polifônico, trazer ideias (pre)concebidas acerca de alguém, de algum fato etc. Os clichês e estereótipos assumem determinados valores nas interações sociais, sendo fomentados nos diversos discursos da coletividade. No caso do pronunciamento na ONU, aqui em estudo, os clichês indiciam a dialogicidade do enunciado (BAKHTIN, 2011, p. 297), uma vez que comportam "ecos e ressonâncias de outros enunciados com os quais estão ligados pela identidade da esfera de comunicação discursiva.".

Ao tratar da Amazônia e do Pantanal, o presidente Bolsonaro põe em cena uma suposta prática de perseguição internacional contra a nação brasileira devido às suas riquezas naturais, ao seu bioma amplo e diversificado. Traçando um discurso de culpabilização de outrem, reinicia um movimento retórico a fim de situar-se na condição de vítima ("somos vítimas de uma das mais brutais campanhas de desinformação sobre a Amazônia e o Pantanal" (§21)), ao mesmo tempo em que desconsidera os dados fornecidos pelos satélites e nega as queimadas amplamente divulgadas por organizações nacionais e internacionais. ${ }^{12}$

12 Consultar: https://www.greenpeace.org/brasil; https:/queimadas.dgi.inpe.br/queimadas/portal-static/estatisticas_estados; https://ipam.org.br/pt; https://brasil.elpais.com/brasil/2020-09-16/descaso-no-pantanal-e-amazonia-ameaca-negocios-do- 
Novamente, o presidente não apresenta explicações plausíveis para os fatos, mantendo um posicionamento discursivo defensivo sobre o seu governo. Segundo o presidente, "somos líderes em conservação de florestas tropicais [...]" (§ 23). No entanto, ao afirmar que o Brasil é um dos países que mais preservam suas florestas tropicais, desconsidera que somos também a nação que apresentou a maior perda desse tipo de cobertura vegetal em 2019, chegando a perder 1, 3 milhão de hectares em 2019. ${ }^{13}$

Um aspecto que merece ser destacado na construção retórica do discurso é o recorrente agenciamento de operadores argumentativos que opõem dois argumentos, em que um acaba prevalecendo sobre o outro: "Mesmo sendo uma das maiores economias do mundo, somos responsáveis por apenas 3\% da emissão de carbono." (§ 24); "apesar da pandemia, verificamos um aumento do ingresso de investimentos" (§ 51) (grifos nossos). Tal recurso, compreendido isoladamente do contexto, pode impedir a apreensão da "multiacentuação do signo ideológico", que não somente reflete, mas refrata as condições da existência, "os interesses sociais multidirecionados nos limites de uma coletividade sígnica, isto é, a luta de classes." (VOLÓCHINOV, 2017, p. 112).

Essa multiacentuação valorativa revela-se de modo mais contundente em determinadas passagens do discurso, a exemplo da acusação feita pelo presidente Bolsonaro de que os caboclos e os índios seriam os responsáveis pelos incêndios na Amazônia, o que foi negado pelo porta-voz do Greenpeace. ${ }^{14}$ Nota-se, no enunciado, o movimento responsivo endereçado à comunidade

brasil-enquanto-governo-se-isenta-de-responsabilidade.html; https://wwwl.folha.uol.com.br/ambiente/2020/08/contrariandobolsonaro-nasa-aponta-que-queimadas-sao-fruto-de-desmatamento.shtml. Acesso em: 29 jun. 2021

13 Consultar: https://blog.globalforestwatch.org/data-and-research/dados-globais-de-perda-de-cobertura-de-arvore-2019. Acesso em: 20 mar. 2021.

14 Consultar: https://oglobo.globo.com/fato-ou-fake/veja-que-fato-ou-fake-no-discurso-de-bolsonaro-na-onu-24654457; <https:// iris.paho.org/handle/10665.2/52280. Acesso em: 30 jun. 2021. 
internacional, que vem denunciando o presidente do Brasil por estar sendo conivente com os ataques de grileiros e garimpeiros às reservas indígenas. No enunciado "Nosso governo [...] Assistiu a mais de 200 mil famílias indígenas com produtos alimentícios e prevenção à covid" (\$12), é possível verificar que o presidente Bolsonaro busca produzir e fazer circular um efeito de verdade, colocando-se, na maioria das vezes, como fonte e origem do dizer.

O efeito de verdade que ele busca imprimir no tecido discursivo parte do entendimento de que aquilo que foi dito tem de ser aceito porque quem o fez tem autoridade para fazê-lo. Em seu discurso, o argumento de autoridade é representado por sua persona - presidente da república -, na tentativa de criar um efeito de que aquilo que é dito por ele possa ser considerado como algo incontestável, sem necessidade de se ancorar em fundamentos com valor de verdade. Assim, o que é posto em jogo pelo projeto enunciativo do presidente Bolsonaro não é a busca, a discussão, a problematização de uma verdade, mas a imposição da palavra pela figura de autoridade, não pelo exercício de autoridade, de legitimidade sobre determinado conhecimento, assunto ou questionamento em pauta. A adesão ao efeito de verdade depende da credibilidade dos sujeitos mobilizados no argumento de autoridade, pois, "diferentemente do valor de verdade, que se baseia na evidência, o efeito de verdade baseia-se na convicção, e participa de um movimento que se prende a um saber de opinião, a qual só pode ser apreendida empiricamente" (CHARAUDEAU, 2005, p. 49).

A partir do $30^{\circ}$ parágrafo, observa-se, na tessitura discursiva do pronunciamento, uma tentativa de convencimento dos países membros da ONU de que o governo brasileiro vinha se pautando 
por uma política de proteção ambiental - "tolerância zero com o crime ambiental.”. Cabe salientar que a gestão do governo do presidente Bolsonaro realizou várias ações contrárias à preservação do meio ambiente, como: corte orçamentário na prevenção de incêndios, demissão de funcionários que apontavam os casos de desmatamentos, desmonte/enfraquecimento do Instituto Brasileiro do Meio Ambiente e dos Recursos Naturais Renováveis (IBAMA) e da fiscalização florestal, além da paralisação do Fundo Amazônia. ${ }^{15}$

É possível apreender, no tecido discursivo, a recorrência da dicotomização e da polarização, na tentativa de culpabilizar aqueles a quem considera como adversários. Ao imputar as culpas e responsabilidades ao outro, o discurso do presidente Bolsonaro apresenta acusações infundadas e ilações sem base científica, a exemplo de excertos em que atribui o vazamento de óleo na costa brasileira, em 2019, como um ato criminoso da Venezuela $(\S 35-\S 37)$.

A tese da "cristofobia", recorrentemente agenciada pelo presidente Bolsonaro em suas falas públicas nas redes sociais e em manifestações a seus apoiadores, é trazida em dois momentos da finalização de seu pronunciamento na ONU: "Faço um apelo [...] pelo combate à cristofobia"; "O Brasil é um país cristão e conservador e tem na família sua base” (§56 e §62). O termo "cristofobia", não explicitado pelo enunciador, somente poderá ser compreendido no contexto ativo e responsivo, uma vez que “toda compreensão é dialógica” (VOLÓCHINOV, 2017, p. 232). Apenas nas relações estabelecidas com outros enunciados concretos, é que podemos construir a significação do termo

\footnotetext{
15 Consultar: https://revistaforum.com.br/politica/bolsonaro/governo-anuncia-corte-de-34-na-verba-de-2020-para-combate-aincendios-na-amazonia; https://wwwl.folha.uol.com.br/ambiente/2020/09/apesar-de-incendios-governo-corta-orcamentodo-ibama-e-icmbio-em-2021.shtml; https://g1.globo.com/natureza/noticia/2020/10/26/fundo-amazonia-tem-r-29-bilhoes-emconta-parados-apos-paralisacao-pelo-governo-bolsonaro-alerta-rede-de-organizacoes.ghtml. Acesso em: 20 mar. 2021.
} 
"cristofobia", entretanto, podemos pressupor a busca de uma interlocução do presidente com o seu fiel eleitorado, em prol de apoio e preservação de uma representatividade religiosa, e com a bancada cristã do Congresso, a qual vem conseguindo ocupar, cada vez mais, vagas no poder legislativo, em municípios e estados brasileiros. Provavelmente, com esse posicionamento "cristão e conservador", o presidente Bolsonaro aposta na possibilidade de alimentar e ampliar sua bolha de eleitores e intensificar e fortalecer o efeito da câmara de ecos, ${ }^{16}$ a fim de promover engajamento e conquistar ainda mais seguidores de seus princípios e crenças.

Ao deixar entrever em seu discurso que há perseguição no Brasil em relação ao povo cristão, o presidente fomenta $o$ processo de marginalização dos sujeitos conforme suas religiões, o que pode propiciar o preconceito, a segregação, a violência em suas mais variadas manifestações. Cabe salientar que, sob o governo do presidente Bolsonaro, as religiões de matriz africana, principalmente o Candomblé e a Umbanda, são as que mais sofrem manifestações de ódio, perseguições e ataques a seus terreiros e templos.

Sob a tese da "cristofobia", há implícito o jogo de manipulação das massas, a prática da dicotomização em relação a políticas de governos anteriores, a polarização, acentuando extremismos, visando a instaurar o medo, a apreensão, o preconceito racial, a intolerância religiosa, concomitantemente à projeção e à veiculação da ideia e imagem de chefe de Estado "salvador da pátria", "guardião dos bons costumes".

\footnotetext{
16 As câmaras de eco referem-se ao resultado da interação contínua dentro das bolhas ideológicas e culturais de informação nos ambientes virtuais. Nesse contexto, os sujeitos interagem, preferencialmente, com pessoas de interesses e opiniões semelhantes, diminuindo sua exposição a perspectivas diferentes (SILVA, 2018). As câmaras de eco funcionam como complexos que reverberam informações, ideias ou crenças amplificadas ou reforçadas pela comunicação e repetição dentro de um determinado sistema. Em seu interior, as fontes dominantes, predominantemente, são inquestionáveis e as opiniões diferentes ou concorrentes são censuradas ou desautorizadas.
} 


\section{Considerações finais}

A partir da análise do discurso proferido pelo presidente Jair Bolsonaro, é possível entrever o cenário de instabilidade instaurado na contemporaneidade, em decorrência dos impactos da infodemia e da desinformação sob os princípios da retórica da pós-verdade. Os posicionamentos axiológicos que emergem do tecido discursivo em exame podem afetar incisivamente a interlocução com a sociedade. Diante disso, é necessário que haja ações de contraposição a esse discurso hegemônico, isto é, sujeitos que manifestem sua responsividade com posicionamento responsável e crítico diante das redes de desinformação.

Nesse sentido, torna-se fundamental o desenvolvimento de práticas de letramento em leitura, nas instâncias formativas, com vistas a promover o necessário diálogo entre a palavra e a construção de "verdades". Dada a (ir)responsabilidade instaurada pela disseminação de desinformações, avulta-se o papel das instituições de ensino no sentido de desenvolver práticas de letramento (SOARES, 2002; COSCARELLI; RIBEIRO, 2011; KLEIMAN, 1995; KLEIMAN; ASSIS, 2016) que dialoguem com a atualidade e que primem pela formação do sujeito crítico e participativo, para que ele consiga responder às demandas da esfera social com responsabilidade, sabendo posicionar-se discursivamente.

Para atuar em sociedade, de modo a exercer a cidadania por meio de posicionamentos críticos e tomadas de decisão pautadas nas relações democráticas e igualitárias, as competências de leitura e escrita, por meio do desenvolvimento de práticas de letramento da informação, são indispensáveis. Fazer uso social desses dois processos, compreender, analisar, refletir, interpretar, 
inter-relacionar, sintetizar e saber avaliar informações consistem em habilidades fundamentais na sociedade contemporânea. Concomitantemente, o desenvolvimento de competências informacionais é crucial para uma efetiva cidadania. A enorme disponibilidade de fontes de informação, juntamente com a oferta de novas possibilidades de produção de conhecimento, demanda qualificação dos processos de seleção e análise de informações e conhecimentos sobre aspectos técnicos, políticos, estéticos e éticos das informações e de seus fluxos de comunicação.

Em tempos de (des)informação, são urgentes o "fortalecimento da alfabetização/letramento midiático, informacional e científico" e o desenvolvimento de políticas públicas educacionais que promovam o desenvolvimento de competências que possibilitem aos sujeitos realizar a avaliação da qualidade a respeito daquilo que é consumido (KOMESU; ALEXANDRE; SILVA, 2020, p. 199-200). Sob o cenário da infodemia, um dos elementos desencadeadores do caos social, a competência crítica em informação pode auxiliar os sujeitos no reconhecimento de desinformações no ambiente digital e diminuir a sua propagação, assim como o caos social. Nesse contexto, as agências de fact-checking desempenham uma função relevante na verificação de informações, sendo aliadas no enfrentamento da infodemia.

Komesu, Alexandre e Silva (2020) salientam também que, no trabalho em sala de aula com as desinformações, em especial no que se refere ao processo de debunking (desmitificação de boatos), o professor pode tomar como referência o passo-a-passo utilizado pelas agências de fact-checking, como: apresentar e explorar fontes seguras e adequadas conforme cada nível de ensino, realizar a navegação por links, confrontar perspectivas, 
discutir acerca da disseminação de informações por meio de algoritmos e assumir responsabilidade ética no tocante ao que é criado, produzido e compartilhado no âmbito digital.

Considerando essa perspectiva, a desinformação deve ser enfrentada por meio de ações formativas para o trabalho com fontes de informação. A escola pode auxiliar os estudantes no que se refere aos recursos e caminhos para que eles consigam analisar criticamente as informações, verificando a autoria e a maneira como foram elaboradas, quais foram os objetivos, se há distorções e de que forma podem ser manipuladas. Desse modo, é importante que as instituições de ensino busquem formar estudantes que saibam pesquisar, selecionar, analisar, avaliar e utilizar adequadamente e com criticidade as informações de que necessitam. As ações de pesquisa devem se orientar pela avaliação das fontes e de sua credibilidade, para que se possam identificar as distinções entre conhecimento, opinião e comentário. Também é essencial que os estudantes sejam provocados a reconhecer as condições de produção, circulação, consumo e reprodução das informações para que percebam sob quais influências, interferências e injunções sociopolíticas essas informações se constituem.

Ao finalizar este artigo, enfatizamos que o investimento em reflexões a respeito da desinformação é premente, visto que ela sempre se fará presente, com efeitos nefastos para a sociedade e repercussões expressivas nas trajetórias e estruturas históricas, sociais, econômicas, políticas e culturais dos sujeitos. Nesse sentido, estudos mais aprofundados podem auxiliar no que se refere ao seu conhecimento, essencialmente no tocante à sua atuação na esfera social, assim como ao seu enfrentamento. 


\section{Referências}

ALLCOTT, Hunt; GENTZKOW, Matthew. Social media and fake news in the 2016 election. Journal of Economic Perspectives, v. 31, n. 2, p. 211-236, 2017. Disponível em: $<$ https://web.stanford.edu/ gentzkow/research/fakenews.pdf $>$. Acesso em: 13 jun. 2021.

AMOSSY, Ruth. Apologia da polêmica. Tradução de Mônica Magalhães Cavalcante. São Paulo: Contexto, 2017.

AMOSSY, Ruth; PIERROT, Anne Herschberg. Stéréotypes et clichés. Paris : Armand Colin, 2015.

BAKHTIN, Mikhail Mikhailovitch. Estética da criação verbal. Tradução de Paulo Bezerra. 6. ed. São Paulo: Martins Fontes, 2011.

BAKHTIN, Mikhail Mikhailovitch. Para uma filosofia do ato responsável. Tradução de Valdemir Miotello e Carlos A. Faraco. 3. ed. São Carlos: Pedro e João Editores, 2017.

CASTELLS, Manuel. A era da informação: economia, sociedade e cultura. A sociedade em rede. 6. ed. São Paulo: Paz e Terra, 2012.

CHARAUDEAU, Patrick. Discurso das mídias. Tradução de Ângela S. M. Corrêa. São Paulo: Contexto, 2005.

COSCARELLI, Carla Viana; RIBEIRO, Ana Elisa. Letramento Digital: aspectos sociais e possibilidades pedagógicas. 3. ed. Belo Horizonte: Ceale; Autêntica, 2011.

DAVENPORT, Thomas. Saving its soul: human-centered information management. Harvard Business Review, v. 72, n. 2, p. 119-131, mar./apr. 1994. Disponível em: <http://wiki. sugarlabs.org>. Acesso em: 1 jul. 2021.

FERRARI, Pollyana. Como sair das bolhas. São Paulo: Armazém da Cultura, 2018. 
FRIAS FILHO, Otávio. O que é falso sobre fake news. Revista USP, n. 116, p. 39-44, 2018. Disponível em: <https://www. revistas.usp.br/revusp/article/view/146576>. Acesso em: 1 jul. 2021.

KALIL, Isabela; SANTINI, Rose Marie. Coronavírus, pandemia, infodemia e política. Relatório de pesquisa. São Paulo/Rio de Janeiro: FESPSP/UFRJ, 2020. Disponível em: $<$ https://www.fespsp.org.br/store/file_source/FESPSP/ Documentos/Coronavirus-e-infodemia.pdf $>$. Acesso em: 10 abr. 2021.

KLEIMAN, Angela B. (org.). Os significados do letramento: uma nova perspectiva sobre a prática social da escrita. Campinas, SP: Mercado de Letras, 1995.

KLEIMAN,Angela B.;ASSIS, Juliana Alves.(org.). Significados e ressignificações do letramento: desdobramentos de uma perspectiva sociocultural da escrita. Campinas, SP: Mercado de Letras, 2016.

KOMESU, Fabiana Komesu; ALEXANDRE, Gabriel Guimarães; SILVA, Larissa Souza da. A cura da infodemia? O tratamento da desinformação em práticas sociais letradas de checagem de fatos em tempos de Covid-19. In: RODRIGUES, Daniella. L. D. I.; SILVA, J. Q. G. (org.). Estudos aplicados à prática da escrita acadêmica: colocando a mão na massa. Belo Horizonte: Editora PUC Minas, v. 3, p. 186-229, 2020.

LEVI, Lili. Real Fake News and Fake Fake News. First Amendment Law Review, v. 16, p.232-327, 2018. Disponível em: https://repository.law.miami.edu/fac_articles/581. Acesso em: 1 jul. 2021.

ORGANIZAÇÃO MUNDIAL DA SAÚDE (OMS). Preguntas y respuestas sobre la enfermedad por coronavirus (COVID-19). 2020. Disponível em: https://www.who.int/ es/emergencies/diseases/novel-coronavirus-2019/advice-forpublic/q-a-coronaviruses. Acesso em: 25 mar. 2021. 
ORGANIZAÇÃO PAN-AMERICANA DA SAÚDE (OPAS). Entenda a infodemia e a desinformação na luta contra a Covid-19. 2020. Disponível em: https://iris.paho.org/ handle/10665.2/52054. Acesso em: 25 mar. 2021.

SILVA, Lucas Eduardo Ferreira de Souza. A credibilidade das informações online na era da pós-verdade. Múltiplos Olhares em Ciência da Informação, [S. l.], v. 8, n. 2, p. 1-14, nov. 2018. Disponível em: https://periodicos.ufmg.br/index.php/moci/ article/view/16899. Acesso em: 9 jul. 2021.

SOARES, Magda. Novas práticas de leitura e escrita: Letramento na Cibercultura. Educação e Sociedade: Campinas, v. 23, n. 81, p. 143-160, dez. 2002. Disponível em: Disponível em: https://www.scielo.br/j/es/a/zG4cBvLkSZfcZnXfZGLzsXb/ abstract/?lang=pt. Acesso em: 1 jul. 2021.

SYED, Nabiha. Real Talk About Fake News: Towards a Better Theory for Platform Governance. Yale Law Journal Forum, v. 127, p. 337-357, 2017. Disponível em: http://www. yalelawjournal.org/forum/real-talk-about-fake-news. Acesso em: 1 jul. 2021.

VOLÓCHINOV, Valentin Nikolaevich. A construção da enunciação e outros ensaios. Organização, tradução e notas de João Wanderley Geraldi. São Carlos: Pedro \& João Editores, 2013.

VOLÓCHINOV, Valentin Nikolaevich. Marxismo e filosofia da linguagem: problemas fundamentais do método sociológico na ciência da linguagem. Tradução de Sheila Grillo e Ekaterina Vólkova Américo. São Paulo: Editora 34, 2017.

WARDLE, Claire; DERAKHSHAN, Hossein. Information Disorder: Toward an interdisciplinary framework for research and policy making. Strasbourg Cedex: Council of Europe, 2017. Disponível em: https://edoc.coe.int/en/media/7495-informationdisorder-toward-an-interdisciplinary-framework-forresearchand-policy-making.html. https://goo.gl/9bsMGi. Acesso em: 13 jun. 2021. 